\title{
O Eu e os Outros Eus: A experiência de Self e Presença em Ambientes Virtuais
}

Paulo Gomes de Sousa Filho ${ }^{1}$

\section{RESUMO}

O aprimoramento das tecnologias de informação e comunicação tem aumentado as possibilidades de interação mediadas pelo computador, assim como o desenvolvimento do ciberespaço tem propiciado novas formas de explorações e descobertas. Com o desenvolvimento dos dispositivos de realidade virtual e também da realidade aumentada, esses ambientes virtuais podem oferecer oportunidades de múltiplas expressões do self a medida que as diferenças sensoriais e perceptuais entre esses ambientes e a realidade tendem a desaparecer. $O$ presente trabalho apresenta uma discussão das possibilidades de vivências propiciadas tanto pela realidade virtual quando pela realidade aumentada e aponta as possibilidades de experimentações do self presentes em um ambiente virtual imersivo em 3D como o Second Life.

Palavras-chave: realidade virtual, realidade aumentada, second life, self

\section{I and Others Me: The experience of Self and Presence in Virtual Environments}

\begin{abstract}
The improvement of the technologies of information and communication has increased the possibilities of interaction mediated by the computer, as well as the development of cyberspace has propitiated new forms of explorations and discoveries. With the development of these devices of virtual reality and also of augmented reality, these virtual environments can offer possibilities of multiple expressions of self as the sensorial and perceptuals differences between these environments and the reality tend to disappear. This article presents a quarrel of the possibilities of experiences propitiated by both, virtual reality and augmented reality and emphasizes the possibilities of experimentations of self that you find in a 3D immersive virtual environment such as the Second Life.
\end{abstract}

Key words: virtual reality, augmented reality, second life, self

\section{INTRODUÇÃO}

\footnotetext{
1 Psicólogo clínico com formação em terapia cognitiva-comportamental, mestre em criatividade, doutorando no Programa de Pós-Graduação em Informática na Educação da UFRGS. Email: kramerdf@hotmail.com
} 
A partir do final do século passado, temos presenciado uma revolução em praticamente todas as áreas da experiência humana como conseqüência de um espetacular desenvolvimento das chamadas Tecnologias da Informação e Comunicação. Aspectos tais como a comunicação mediada por computador, uma concepção diferenciada de espaço-tempo, uma nova relação do pensar além da indução e dedução, entre outros, têm provocado uma ruptura nas relações do homem com o seu ambiente físico e social e na construção de sua subjetividade.

Nesse contexto, um dos aspectos mais interessantes tem sido o estudo das relações mediadas por computadores. Moura (1998) afirma que, com as novas formas de interação e com o discurso engendrado através da mídia interativa mediada pelo computador, surge um espaço social que favorece as novas formas de relacionamento, distribuição de papéis e trocas sociais. Gackenbach (1998) sugere que a liberdade para recriar aspectos do self online permite a exploração e a expressão de múltiplos aspectos da existência humana. O self, na perspectiva de Rasera, Guanaes \& Japur, (2004) é visto aqui como povoado por "múltiplas e contraditórias possibilidades de ser, para o qual se ampliam as oportunidades de relacionamento com os outros, se complexificam os diálogos internos e aumenta a dificuldade de compromisso com uma identidade assimilável à idéia de unicidade" (p. 159).

A experimentação desses "outros eus" fica evidente nas relações vivenciadas nas comunidades virtuais. As pesquisas relacionadas a estas comunidades sempre mencionam o uso de máscaras para idade, raça, gênero e classe social. Máscaras para quase todos os aspectos da identidade, assim como o efeito de desinibição que a comunicação mediada por computador propicia.

Nesse sentido, os ambientes virtuais imersivos em 3D tais como o Second Life estão na linha de frente do que Scola (2005) chamou de "Internet Física". Estes ambientes permitem aos usuários se comunicarem entre si através de avatares, suas personas digitais, ao invés de apenas utilizarem os textos escritos. Os ambientes de simulação online parecem afetar as formas de expressão do self ao diminuírem a distância existencial entre os seus usuários facilitados pela interação propiciada pelo meio vivencial.

A natureza amorfa do ciberespaço tem sido evidenciada no momento em que se teoriza sobre a fragmentação do físico, sobre a projeção do self no virtual, como oportunidades para exploração e descoberta, e como também para uma desrealização do indivíduo. Com o desenvolvimento e aprimoramento dessas tecnologias, novas possibilidades de interação têm surgido permitindo aos internautas experiências de presença ainda não muito bem equacionadas em suas consequiências.

Sendo assim, a luz do desenvolvimento da realidade virtual, realidade aumentada e novas formas de comunicação mediada pelo computador como o Second Life, teorizamos sobre a potencialidade de experimentação do sujeito ao imergir em ambientes virtuais que em um futuro próximo poderão ser similares ao seu mundo presencial.

\section{O Virtual}

Na perspectiva de Parente (1993), a contemporaneidade é definida como a era das tecnologias do virtual. Lévy (1996) faz a pergunta 'O que é o virtual?', deixando clara a dificuldade encontrada na busca por uma definição, já que não se trata de uma 
noção clara, nem mesmo compreendida de forma aproximada entre aqueles que têm se dedicado à compreensão desse tema.

Em Quéau (1993), percebemos uma discussão da virtualidade por aproximação à simulação e às imagens de síntese. Este autor discute os 'espaços virtuais' como caracterizados pela metamorfose contínua, labirintos informacionais em constante regeneração: "campos de dados onde cada ponto pode ser considerado como a porta de entrada para um campo de dados, em direção a um novo campo virtual, ele mesmo conduzindo a outros espaços de dados.” (p. 96). Para este autor, o virtual é efeito de uma tendência à desrealização, sendo aquilo que substitui a realidade, o que está ao lado do real ali onde "a fronteira entre o verdadeiro e o falso se torna cada vez mais impalpável” (p.96). Nesse sentido, o virtual é visto como negativo, o oposto do real.

Pierre Lévy contribui com um outro enfoque onde não existe oposição entre realidade e virtualidade. Para este autor, "virtualização não é uma desrealização[...], mas uma mutação de identidade, um deslocamento do centro de gravidade ontológico do objeto considerado." (17-18). Estão entre as características da virtualização o desprendimento do aqui e do agora, a não-presença em um sentido obtido, segundo Lévy, pela religião, os sistemas simbólicos, a imaginação e a memória, muito antes da informatização e das redes digitais. Nesse sentido, os novos dispositivos de realidade virtual que tem a interatividade como característica evidente, promovem a expansão das possibilidades de múltiplas presenças, à medida que estes ampliam as chances de interação e comunicação permitindo formas de expressão e vivências com conseqüências ainda pouco compreendidas.

\section{Realidade Virtual e Interatividade}

Realidade virtual é uma expressão que tem povoado o imaginário das pessoas a partir dos filmes de ficção científica assim como do aparecimento de jogos online de última geração, entre os quais temos o Second Life.

Coates (1992) citado por Steuer (1993) aponta que realidade virtual são simulações eletrônicas de ambientes experienciadas através de mecanismos especiais (óculos, roupas, luvas) que permitem ao usuário interagir em situações realísticas em três dimensões. Já para Greenbaum (1992) citado por Steuer (1993) realidade virtual é um mundo substituto preenchido com imagens geradas por computador que respondem aos movimentos humanos. Estes ambientes simulados são usualmente vivenciados com a ajuda de mecanismos tais como os citados anteriormente. Temos ainda a percepção de Krueger (1991) citado por Steuer (1993) que chama atenção para o fato de que o termo mundo virtual, estação de trabalho virtual e cockpit virtual foram utilizados para descrever projetos específicos sendo que em 1989, Jaron Lanier cunhou o termo realidade virtual para colocar todos os projetos virtuais em uma única rubrica. $\mathrm{O}$ termo então se refere a realidades em três dimensões implementadas com o uso de dispositivos eletrônicos utilizados pelo usuário e acoplados ao computador.

Essas três definições variam em alguns aspectos, mas deixam clara a noção de que tanto existe uma simulação eletrônica de ambiente como o uso de dispositivos tais como sistemas de óculos e luvas como a forma de acessar esses ambientes.

Contrariamente aos autores citados anteriormente, e mais de acordo com a nossa percepção de virtual, para Steuer (1993), o uso de dispositivos ou artefatos é dispensável para caracterizar o termo. A chave para definir realidade virtual é o conceito 
de presença. Este autor propõe que "realidade virtual é definida como um ambiente real ou simulado no qual o indivíduo que percebe experiencia telepresença" (p.76). Presença foi definida como "a experiência subjetiva de estar em um lugar ou ambiente, mesmo quando fisicamente localizado em outro" (witmer e Singer, 1998). Como aponta Heeter, presença (2003) é o processo de discernir e validar a existência do self no mundo natural como um processo no qual os humanos tem se engajado desde o nascimento. O senso de presença em um ambiente virtual deriva dos sentimentos de como se você existisse dentro, mas como uma entidade separada de um mundo virtual que também existe.

O ciberespaço, como a mente, não é um espaço físico, mas um espaço virtual, sem extensões, distâncias ou massa. Similarmente, a realidade virtual não tem forma física ou massa. O tamanho do disco rígido não está relacionado com o tamanho do conteúdo do ciberespaço. A realidade virtual é criada pela interatividade.

Uma questão importante que devemos evidenciar é a própria noção de interatividade. Este termo tem sido banalizado servindo para qualificar qualquer sistema cujo funcionamento permite ao usuário algum nível de participação. Silva (2007) nos lembra que

"o cinema cujas cadeiras balançam sincronizadamente com o filme exibido é chamado de cinema interativo. Interativo apenas porque as cadeiras balançam, mas ninguém está interagindo com coisa alguma. Na televisão, quando o programa supõe respostas dos telespectadores por telefone é chamado de TV interativa. Interativa somente porque as pessoas respondem $x$ ou y, sim ou não. No teatro, quando os atores se envolvem diretamente com pessoas da platéia, previamente preparadas ou não, é teatro interativo".

Em Lévy (1999) "a interatividade assinala muito mais um problema, a necessidade de um novo trabalho de observação, de concepção e de avaliação dos modos de comunicação do que uma característica simples e unívoca atribuível a um sistema específico" (p.82). Por outro lado, Lemos (2000) aponta que interatividade é um caso específico de interação, a interatividade digital, compreendida como um tipo de relação tecno-social, ou seja, como um diálogo entre homem e máquina, através de interfaces gráficas, em tempo real.

Com a digitalização das Tecnologias de Informação e Comunicação observamos a configuração de um ambiente propício para o desenvolvimento da interatividade, mas o seu significado extrapola esse âmbito. Silva (1998) chama atenção para o fato de que a interatividade está na "disposição ou predisposição para mais interação, para uma hiper-interação, para bidirecionalidade - fusão-emissão-recepção - para participação $e$ intervenção" (p.29). Interatividade implica, pois na abertura de múltiplos canais de participação, comunicação e trocas.

"a disponibilização consciente de um mais comunicacional de modo expressivamente complexo, e, ao mesmo tempo, atentando para as interações existentes e promovendo mais e melhores interações - seja entre usuário e tecnologias comunicacionais (hipertextuais ou não), seja nas relações (presenciais ou virtuais) entre os seres humanos." (Silva, 1999, p.155) 
O grau de interatividade, de como afetamos e somos afetados em um ambiente virtual, da magnitude de nossas trocas nesse ambiente, podem ser determinantes na construção de nosso sentimento de presença nesse ambiente.

\section{Realidade Aumentada}

Realidade aumentada é um campo da pesquisa com computadores que lida com a combinação do mundo real com dados gerados por computador. Esta nova tecnologia poderá obscurecer a fronteira do que é real e do que é gerado por computador aumentando o que vemos, ouvimos, sentimos e cheiramos.

Realidade aumentada é uma variação dos ambientes virtuais ou realidade virtual como é mais comumente chamada. Como aponta Azuma (1997), nos ambientes virtuais, enquanto imerso, o usuário não pode ver nada do que acontece no mundo a sua volta. Em contraste, a realidade aumentada permite ao usuário ver o mundo real, com objetos virtuais superpostos compondo esse mundo real. A realidade aumentada suplementa a realidade ao invés de substituí-la completamente. É uma combinação da cena real vista pelo usuário e uma cena virtual gerada pelo computador que aumenta a cena com informação adicional. Esse aumento pode assumir as mais variadas formas sendo que, em todas essas formas, a realidade aumentada apresentada ao usuário aumenta a performance e a percepção do mundo da pessoa.

No espectro entre realidade virtual, ambientes gerados por computador e o mundo real, a área da realidade aumentada está mais perto da experiência do mundo real ao adicionar gráficos, sons, cheiros e experiências táteis ao mundo natural como ele é. (fig. 1)

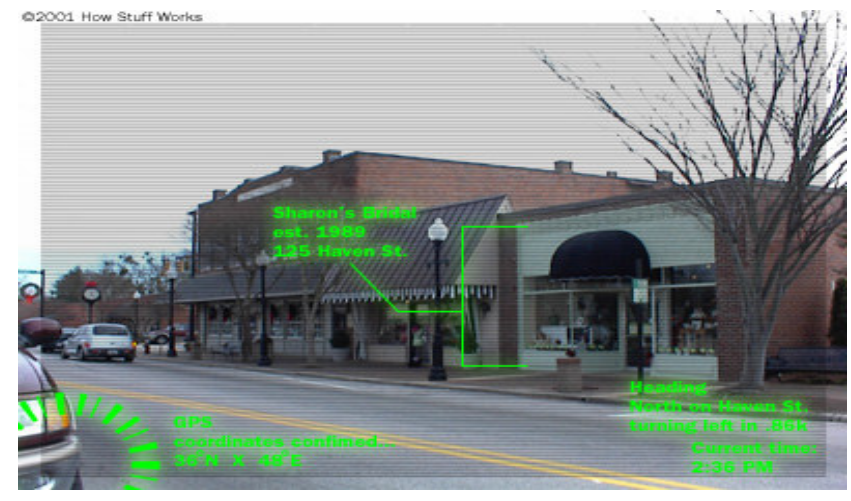

Figura 1 - Realidade aumentada

A realidade aumentada irá transformar profundamente a maneira pela qual nós percebemos o mundo. A idéia básica da realidade aumentada é sobrepor gráficos, áudio e outros aprimoramentos dos sentidos, sob um ambiente de mundo real em tempo real. Por exemplo, imagine-se andando ou dirigindo. Com um equipamento de realidade aumentada que eventualmente poderá ser um simples óculos, gráficos informativos aparecerão em seu campo de visão e o áudio coincidirá com tudo que você vê.

A realidade aumentada tem potencial para ser utilizada em quase todo campo de trabalho incluindo a indústria de construção civil, militar (que tem pesquisado intensivamente nessa área), informações instantâneas (por exemplo, um estudante poderia estar imerso em uma recriação de um evento histórico), jogos eletrônicos (sendo o videogame projetado no mundo real a sua volta e você será um dos personagens). 
Outro uso é a capacidade de melhorar e ampliar as aplicações de mídia tais como telas virtuais pseudo holográficas, e holodecks virtuais (permitindo que a imagem gerada por computador interaja com a audiência). Com mais tempo de pesquisa, pensamos que este campo poderá gerar um ambiente similar ao holodeck de jornada nas estrelas, um ambiente onde o sujeito pede para o computador o tipo de ambiente físico e social no qual deseja estar inserido e então, passa a interagir com esse ambiente e seus personagens.

Podemos fazer um jogo de imaginação e pensar em um ambiente onde tanto a realidade virtual quando a realidade aumentada poderiam ser utilizadas conjuntamente. Milgram et al. (1994) descreveram uma taxonomia para identificar como a realidade aumentada e a realidade virtual estão relacionadas. Ele define como continuum Realidade-Virtualidade (fig. 2).

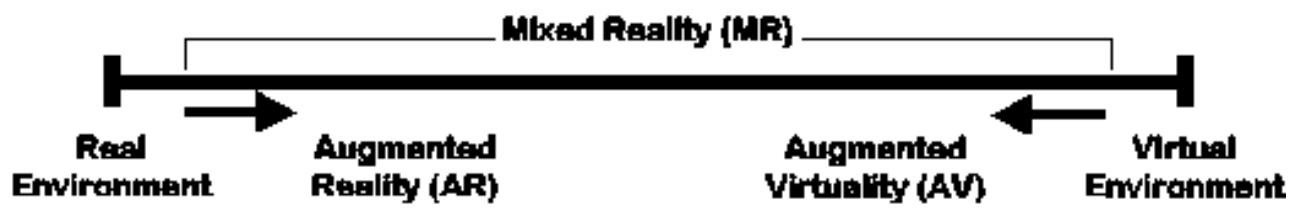

Figura 2 - Continuum Realidade-Virtualidade de Milgram

Segundo estes autores, o mundo real assim como um ambiente totalmente virtual, estão de cada lado de um continuum com a região central chamada de Realidade Mista. A realidade aumentada predomina perto do final do mundo real com a percepção sendo o mundo real aumentado por dados gerados por computador. Virtualidade aumentada é um termo criado por Milgram para identificar sistemas os quais são em sua maioria sintéticos com alguns aspectos do mundo real adicionados. Esta distinção poderá ser útil à medida que a tecnologia se desenvolve e os elementos virtuais de uma cena se tornam menos distintos daqueles do mundo real.

Tanto a realidade virtual quanto a realidade aumentada são tecnologias que permitem uma alteração da gama de estímulos provenientes do ambiente seja ele presencial ou virtual, proporcionando novas possibilidades sensoriais de interação com a realidade. $\mathrm{O}$ desenvolvimento e utilização de dispositivos virtuais imersivos tais como simuladores e jogos abrem uma pletora de novas possibilidades que apenas começam a ser conhecidas e a se popularizarem em jogos eletrônicos tais como o Second Life.

\section{Second Life - O mundo é virtual, mas as emoções são reais}

O Second Life, sistema dos laboratórios Linden, é um mundo em 3D ou "metaverso". Os usuários acessam o sistema online com um cliente proprietário e interagem com o conteúdo e outros "residentes". Com atributos únicos inclui ferramentas simples para construção de objetos em 3D e ferramentas de script para conteúdo interativo incluindo conectividade com páginas web externas assim como recursos da Internet. O Second Life apresenta aprimoramentos quando comparado com seus predecessores. Primeiro, possui uma plataforma que é completamente livre de uma narrativa imposta pelos editores. Segundo, oferece ferramentas simples para modificar ou moldar conteúdos. Os usuários constroem com uma paleta limitada de objetos primitivos (prims) incluindo cubos, esferas, cones etc. Menus simples permitem ao usuário ajustar o tamanho dos objetos e a mapear imagens em sua superfície. Por último, programadores amadores criam aplicações interativas complexas em Linden 
Scripting Language. Eles criam objetos que reagem inteligentemente ao toque. Um objeto pode mesmo ser programado para se mover independentemente e controlar outros itens para criar ferramentas de construção complexas (Linvingstone e Kemp, 2006).

Ao entrar no Second Life, a pessoa escolhe um avatar (fig.2), termo hinduísta para nomear um ser transformado em Deus e que passou a designar o boneco construído com base no que o internauta gostaria de ser e ter ao reencarnar online. Muitos inventam uma espécie de personagem e passam a representá-la durante sua permanência no metaverso. Para Karp (em Lopes, 1999)

Os cibernautas não necessariamente se apresentam em sua configuração real, na maioria das vezes surgem na interface como avatares, ou seja, uma das possibilidades de representação. Percebo que este avatar na rede, mostra as várias possibilidades, de modos-de-ser, que um internauta cria para se apresentar da mesma maneira que um ente assume seus modos-de-ser peculiares em sua relação com seu mundo. Posso ser aluno, filho, namorado, e assim por diante (p.34).

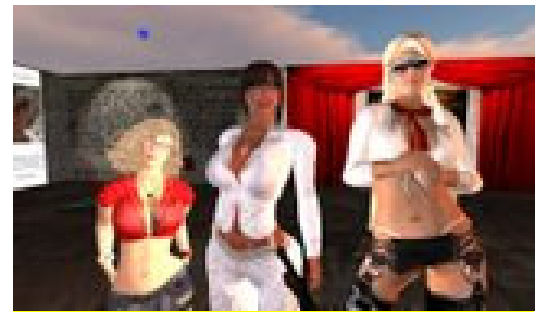

Figura 3 - avatares do Second Life

Já Young (em Prado, 1998), diz existirem necessidades psicológicas inadequadas que são satisfeitas no ciberespaço. Uma delas é o fenômeno das Personalidades Desreprimidas. O outro fenômeno trata de Reconhecimento e Poder, onde essas personas virtuais permitiriam aos indivíduos obter reconhecimento e atingir o poder. Esse aspecto é enfatizado no diálogo abaixo:

"Que lugar é esse?" Eu perguntei. "A festa é aqui?". Um homem veio em minha direção. Acima da sua cabeça flutua um nome e um título: Xaman, mestre do Second Life. Ele me pergunta o que eu quero ali, pois ele poderia me dar tudo o que eu quisesse.

Sobre essa questão, Rheingold (2000) aponta como é poderoso o grau de ligação que o jogador possui com o seu personagem ao refletir sobre as identidades virtuais alternativas. Nesses jogos formam-se relacionamentos que em muitas vezes vão apresentar ligações mais fortes do que os relacionamentos vivenciados no mundo presencial.

"e voce está... apaixonada?" eu perguntei. "Definitivamente. Eu o amo muito", disse xxcentric girl. "Apaixonada tipo na vida real?" Ela não hesitou. "Sim, claro. Com todo o meu amor real. Nós falamos toda noite aqui via voz e sinceramente, gosto mais de estar com ele do que com os que namorei na vida real"

A identidade virtual em um jogo online é muito importante para o jogador. Pode ser tão importante ao ponto do jogador passar a ter pequenos abalos emocionais ao vivenciar certas 
experiências conseqüências da forte conexão emocional construída com relação a seu personagem.

"No mundo do Second Life eu sou Mandrix, uma versão punk-eletrônico de mim mesmo, com cabelos azuis, várias correntes e um corpo perfeito. Semana passada uns idiotas não me deixaram entrar em uma festa porque me disseram que não era pro meu tipo. Fiquei a semana pensando nessa merda”

Em alguns jogos online do tipo MUDs não existe a possibilidade de recuperação de um personagem se ele por alguma razão vier a morrer. O impacto da perda de seu personagem é vivenciado pelo jogador sob fortes emoções. Rheingold (2000) cita uma conversa na qual esse impacto fica evidente:

Perder seu personagem em um jogo é algo absolutamente terrível. É a pior coisa que pode acontecer com você e as pessoas ficam realmente chateadas. Não é como dizer "que pena, perdi meu personagem" da mesma maneira que você diz "que pena, perdi meu sapato". Não é nem mesmo como dizer "que pena, perdi meu personagem" do mesmo jeito que se diz "que pena, perdi meu hamster de estimação". Está mais para "eu morri. Eles me mataram". Não é como dizer "eu acabei de perder todo aquele tempo e esforço que eu coloquei no meu personagem”. A sensação esta mais para "eu acabei de morrer, isso é terrível! Ó meu Deus, estou morto, vazio.".

Para Campos (em Farah, 2004), os termos persona, personalidade e personagem têm a mesma raiz cujo significado nos remete à máscara. Desde a Grécia antiga registrase o uso de máscaras. Elas nos permitem agir e ser de formas diferentes do que somos, ou até mesmo sermos de forma igual ao que nos apresentamos. Por um lado, a máscara nos esconde e nos libera para comportamentos que de outro modo, não seriam adequados. Protege da sanção social. Posso experimentar outros modos-de-ser de forma protegida. Quando o indivíduo está imerso no ambiente, totalmente cercado por imagens, sons e estímulos cinéticos, aquela passa a ser sua experiência de mundo. $\mathrm{O}$ espaço digital passa a integrar o espaço físico e novas sensações e percepções são experienciadas corporalmente pelo sujeito.

\section{Considerações finais}

O Second Life permite então, um estreitamento do mundo físico e do mundo virtual ao virtualizar não só as ações psicomotoras dos cibernautas, mas também diminuir a distância existencial entre eles permitindo afetar o outro e, na via contrária, ser também afetado por este outro. A interatividade do ambiente é o vetor principal dessa dinâmica.

Esse universo virtual apresenta potencialidades a serem exploradas pelo desenvolvimento da tecnologia relacionada tanto com a realidade virtual quanto com a realidade aumentada. A integração dessas tecnologias poderá em um futuro próximo propiciar ao experimentador novas formas de sentir a presença, não controlando um avatar, mas sendo o próprio avatar e interagindo com outros de uma forma até agora não experimentada. Os novos sistemas virtuais imersivos poderão revolucionar a forma como damos significado e subjetivamos nossas vivências.

Pensando a natureza simbólica da percepção, a luz dos teóricos da fenomenologia, esta incorpora uma constituição ativa do sujeito que percepciona. Utilizando ambientes imersivos de realidade virtual ou ampliando suas possibilidades 
com a realidade aumentada, mediados por tecnologias onde o computador assume um papel central, o sujeito constrói novos significados para suas experiências sensoriais.

Até que ponto nossa vivência nessa segunda vida não será mera repetição dos comportamentos da primeira com seus valores, preconceitos, medos, ansiedades, significados, fobias?

Penso que não existem possibilidades de uma fragmentação no sentido de criar uma personalidade completamente desvinculada de sua história peculiar de condicionamentos e aprendizagens. Em outras palavras, tenderemos a levar para esse metaverso, os comportamentos aprendidos em nossa vida presencial. Essa vivência "corporal" no ciberespaço vai deixar suas marcas modificando nossos modos de existir, de perceber, de pensar, de ser no mundo.

Se a construção de nossa subjetividade é forjada na relação com o mundo social e com o mundo físico, teremos então que juntar a esses um novo mundo: o metaverso.

\section{Referâncias Bibliográficas}

Azuma, R. T.. A survey of augmented reality. Teleoperators and Virtual Environments 6, 4, 355-385, 1997.

Baños, R. M.; Botella, C.; Garcia-Palacios, A.; Villa, H.; Perpiña, C.; e Alcañiz, M.. Presence and reality judgment in virtual environments: A unitary construct? Cyberpsychology and Behavior, v.3, n. 3, 2000.

Campos, I. F. Identidade virtual - Os nicknames e os personagens virtuais. Em Farah, R. M. (Org.). Psicologia e informática - O ser humano diante das novas tecnologias. São Paulo: Ofiicina do Livro, 2004.

Gackenbach, J.. Psychology and the Internet. Intrapersonal, interpersonal and transpersonal implications. San Diego: Academic Press, 1998.

Heeter, C. Reflections on Real Presence by a Virtual Person. Presence: Teleoperators \& Virtual Environments, Vol. 12, No. 4, 2003.

Levy, P. O que é virtual. São Paulo: Ed. 34, 1996.

Linvingstone, D. e Kemp, J. Proceedings of the First Second Life Education Workshop, Part of the 2006 Second Life Community Convention, Fort Mason Centre, San Francisco, Ca, 2006.

Lemos, A.. Anjos interativos e retribalização do mundo. Sobre interatividade e interafaces digitais. Disponível em:

http://www.facom.ufba.br/pesq/cyber/lemos/interac.html. Acesso em 28 de Julho de 2008.

Lévy, P.. Cibercultura. São Paulo: Ed. 34, 1999.

Lopes, P. A. As relações interpessoais via Internet nas salas de bate-papo (chats). Trabalho de conclusão de curso. PUC-SP. São Paulo, 1999.

Milgram, P, Takemura H., Utsumi A. Kishino F.. Augmented Reality: A Class of Displays on the Reality-Virutality Continuum. In: Proceedings SPIE Vol. 2351:

Telemanipulator and Telepresence Technologies, 282-292, 1994.

Moura, M. L. S.. Interação mediada por computador e alguns resultados de investigações psicológicas. Psicologia: Teoria e Pesquisa, Vol. 14 n. 1 Jan/Abr (6975), 1998. 
Parente, A. (org.). Imagem máquina. A era das tecnologias do virtual. Rio de Janeiro: Ed.34, 1993.

Prado, O. Z. Pesquisa Internet e comportamento - Um estudo exploratório sobre as características de uso da Internet, uso patológico e sobre a pesquisa online. Disponível em http://www.netpesquisa.com/textos/texto1.htm. Acessado em 11/06/2008.

Quéau, P. O tempo do virtual. In: Parente, A. (org.). Imagem máquina: A era das tecnologias do virtual. Rio de Janeiro: Editora 34, 1993.

Rasera, E. F.; Guanaes, C.; e Japur, M.. Psicologia, ciência e construcionismos: dando sentido ao self. Psicologia: Reflexão e Crítica, 17(2), PP. 157-165, 2004.

Rheingold, H.. The virtual community: Homesteading on the electronic frontier. $2 \mathrm{~d}$ ed. Cambridge, Mass.: MIT Press, 2000.

Scola, N.. Avatar politics: The social applications of Second Life. Report for the Institute for Politics, Democracy, and the Internet. Disponível em: www.ipdi.org. Acessado em 14/10/2008.

Steuer, J. Defining virtual reality: Dimensions determining telepresence. Journal of Communication, 42(4):73-93, 1993.

Silva, M.. O que é Interatividade. Boletim Técnico do Senac, v.24, n.2 maio/ago, 1998. Silva, M.. Um convite à interatividade e à complexidade: novas perspectivas comunicacionais para a sala de aula. In: Gonçalves, M. A. R. (org.). Educação e cultura: pensando em cidadania. Rio de Janeiro: Quartet, 1999.

Waterworth, E. L. e Waterworth, J. A. Focus, locus, and sensus: The three dimensions of virtual experience. Ciberpsychology and Behavior, v. 4, 2, 2001.

Witmer, B. G. e Singer, M. J.. Measuring presence in virtual environments: A presence questionnaire. Presence, Vol. 7, No. 3, 1998, 225-240. 